- 9 класс - прогресии;

- 10 класс - экономический смысл производной;

- 11 класс - финансовая математика.

Другими словами, учимся везде находить основание пирамиды «Процент»0,01a, чтобы понимание было устойчивым, а результат предсказуемым.

Десять лет использования метода реконструкции позволили достигнуть определенных результатов. Обучающиеся становятся победителями и призёрами окружного этапа всероссийской олимпиады школьников, успешно участвуют в научноисследовательских конференциях школьников различного уровня, расширяя границы интерпретации математических понятий, качество выполнения ВПР не ниже 85\%, результаты ОГЭ и ЕГЭ выше средних значений по России и региону.

А самое главное, что метод реконструкции позволяет обучающимся осмыслить изучаемый материал на личностно-значимом уровне и получить иные эмоции от урока математики, поняв, что там не все так трудно, как изначально представлялось.

$$
* * *
$$

1. Брунер Дж. Психология познания. М.: Прогресс, 1977. 256 с.

2. Налимов В.В. В поисках иных смыслов // М.: издательская группа Прогресс, 1993. - 280 с.

3. Рыбакина Н.А. Компетентностно-контекстная модель обучения и воспитания в общеобразовательной школе // Образование и наука. 2017. Том 19 №2. С. 31-50.

4. Рыбакина Н.А. Принцип «системности и систематичности» как фактор развития человека в системе непрерывного образования // Наука - образование - профессия: системный личностноразвивающий подход: сборник статей / под общ. ред. Л.М. Митиной. М.: Издательство «Перо», 2019. C.509-512.

\title{
Смирнова С.И. \\ Использование математических заданий творческого характера с целью развития вариативности мышления младших школьников
}

Петрозаводский государственный университет (Россия, Петрозаводск)

doi: $10.18411 / l j-07-2021-153$

\section{Аннотация}

В статье рассматривается значимость формирования вариативности мышления младших школьников в контексте становления творческой деятельности. Приводятся требования к организации творческой деятельности, виды и примеры заданий творческого характера.

Ключевые слова: творческая деятельность, задания творческого характера, вариативность мышления.

\section{Abstract}

The article considers the significance of the formation of the variability of thinking of younger schoolchildren in the context of the formation of creative activity. The requirements for the organization of creative activity, types and examples of exercises of a creative nature are given.

Keywords: creative activity, exercises of a creative nature, variability of thinking.

На современном этапе развития общества возрастает потребность в креативных людях, умеющих мыслить нестандартно, творчески. Чтобы быть успешным в дальнейшем обучении и в профессиональной деятельности, очень важно развивать неординарность мышления как можно раньше. Творческая деятельность способствует лучшему запоминанию информации, более качественному развитию личности, 
развивает интерес у обучающихся и способствует более плодотворному протеканию учебного процесса. В ходе творческой деятельности учащиеся усваивают различные способы решения всевозможных задач, что способствует развитию вариативности мышления.

Д. Б. Богоявленская указывает на то, что творчество является ситуативно нестимулированной активностью, проявляющейся в стремлении выйти за пределы заданной проблемы [3]. По мнению И. Я. Лернера, учащиеся в процессе творчества создают субъективно новое, при этом проявляя свою индивидуальность [7]. В. Н. Дружинин связывает творческое мышление с преобразованием знаний (сюда он относит воображение, фантазию, порождение гипотез и прочее) [5]. Суть творческого мышления, по Я. А. Пономареву, сводится к интеллектуальной активности и чувственности (сензитивности) к побочным продуктам своей деятельности [8].

Важность выявления, поддержки и сопровождения детей, способных к творческому мышлению, имеющих творческие способности, на что не раз указывалось в основных документах, дающих ориентиры развитию системы образования, приводит среди прочих к проблеме развития вариативности мышления обучающихся.

Вариативность мышления, по М. М. Кашапову, - это комбинирование различных вариантов (образцов) возможного разрешения затруднений в конкретной ситуации, нахождение разнообразных способов решения конкретной задачи [1].

Для развития вариативности мышления необходимы определенные условия, которые благоприятствуют его формированию. Такими условиями, являются: создание творческой обстановки; предоставление учащимся свободы в выборе деятельности, в чередовании дел, в продолжительности занятий одним делом; предоставление младшим школьникам возможности для самостоятельного решения задач, требующих максимального напряжения сил; доброжелательная помощь (не подсказка) взрослых, как вариант, в форме сотворчества и т. п.

Творчество - это деятельность, порождающая нечто качественно новое, никогда ранее не бывшее... характеризуется неповторимостью (по характеру осуществления и результату), оригинальностью и общественно-исторической (а не только индивидуальной) уникальностью. При понимании творчества как получения объективно нового результата деятельности вообще невозможно говорить о творческой деятельности учащегося в процессе обучения. Но можно оценивать субъективный характер новизны полученных результатов: школьник достигает новых для себя результатов, а общество получает субъекта с новообразованиями мыслительного процесса. При таком понимании творчества определенная деятельность учащихся может считаться творческой [6].

В педагогической и методической литературе можно встретить деление учебных заданий на творческие и нетворческие. Задания творческого характера - это задания, требующие от учащихся самостоятельного получения нового вывода на основе наблюдений, анализа условий выполнения того или иного задания. Это задания, которые способствуют проявлению у детей активной мысли, творчества. Задания творческого характера не имеют определенного законченного ответа, поскольку решающий может по мере своих склонностей неограниченно углубляться в изучение поставленного вопроса [4].

Задания творческого характера - это такие задания, при выполнении которых ученик выполняет что-то новое для себя. Так, в поисках решения ученик достигает решения другим способом, чем тем, который был показан в классе. Этот способ решения и является для ученика открытием, творчеством.

Для развития творческого мышления и воображения ученикам полезно предлагать задания следующих видов: классификация объектов, ситуаций, явлений по различным основаниям; установление причинно-следственных связей; установление взаимосвязи и выявление новых связей между системами; рассмотрение системы в 
развитии; формулирование предложений гипотетического характера; выделение противоположных признаков объекта; выявление и формулирование противоречия; разделение противоречивых свойств объектов в пространстве и во времени, и др.

Как для освоения любым видом деятельности, так и для творческой деятельности, важным является накопление каждым учащимся опыта осуществления самостоятельной деятельности творческого характера. В обучении математике, например, при обучении младших школьников решению сюжетных задач, возможно использование следующих видов заданий творческого характера [2]:

1) решение задач повышенной трудности,

2) решение задач несколькими способами,

3) решение задач с недостающими или лишними данными,

4) решение задач, имеющих несколько решений (правильных ответов),

5) составление и преобразование задач:

- постановка вопроса к данному условию или изменение данного вопроса;

- составление условия задачи по данному вопросу; подбор числовых данных или их изменение;

- изменение числовых данных задачи так, чтобы появился новый способ решения или, наоборот, чтобы один из способов решения стал невозможен;

- изменение условия задачи так, чтобы задача решалась другим действием;

- исследование решения (сколько способов решения имеет задача? при каких условиях она не имела бы решения? какие приемы наиболее целесообразны для поиска решения этой задачи? возможны ли другие методы решения?);

- составление аналогичной задачи;

- составление обратных задач; составление задач по иллюстрациям;

- составление задач по данному решению;

- преобразование задач в задачи родственных им видов;

- составление задач по моделям,

6) сравнение текстов и/или решений задач,

7) моделирование на различных этапах процесса решения задачи.

Приведем примеры заданий творческого характера для обучающихся начальной школы.

- Сколько лучей с общим началом достаточно провести, чтобы образовалось два угла?

- Сколько различных трехзначных чисел можно составить из цифр $0,1,2$, 3, если цифры в числе не должны повторяться?

- Карлсон съел на завтрак 5 булочек, 6 мороженых, 2 ананаса, 3 шоколадки и 4 груши. Сколько фруктов съел Карлсон на завтрак? (задача с лишними данными);

- Найдите сумму первых ста натуральных чисел;

- Вычислите разными способами значение выражения 125 · 64. Выберите более рациональный способ (или способ, который вам больше нравится или более понятен). Придумайте еще несколько числовых выражений, значения которых можно найти этим же способом;

- Выберите схематический чертеж, соответствующий задаче: «В каждом из двух ящиков находится по 17 кг яблок. Для приготовления компота в школьной столовой использовали 5 кг яблок. Какова масса оставшихся яблок?». Придумайте задачи для двух других схем. 


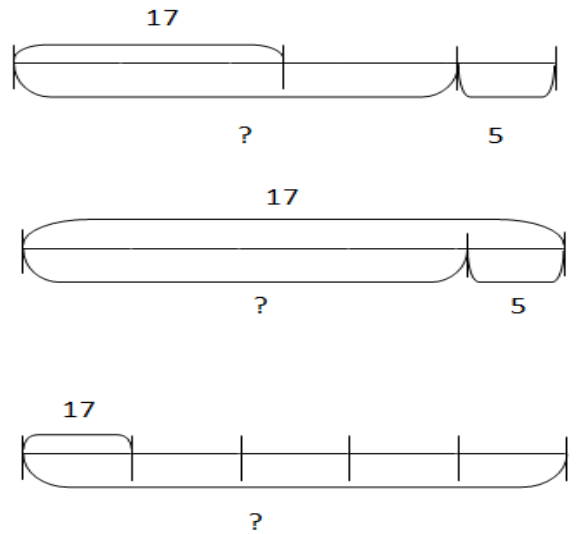

Анализ опыта учителей начальных классов позволяет сделать вывод о том, что на уроках используются разнообразные виды заданий, способствующих развитию у младших школьников вариативности мышления, например, геометрические ребусы, кроссворды, игры «Верю - не верю», «Внимание» и другие, решение частичнопоисковых задач, задания на выявление закономерностей, распределение объектов на группы, отыскание ошибок...

Творческая деятельность должна стать неотъемлемой частью образовательного процесса школьников. Выполняя творческие задания, дети находятся в такой ситуации, что, создавая что-либо новое, они получают новые знания самостоятельно, это способствует лучшему усвоению и запоминанию этой информации.

$$
* * *
$$

1. Активные методы обучения и воспитания: психолого-педагогический тренинг креативности: Методические указания / Сост. М. М. Кашапов. Яросл. гос. ун-т. Ярославль, 2001. 39 с.

2. Бантова М. А. Методика преподавания математики в начальных классах. Москва : Просвещение, 1984. C. 239-241.

3. Богоявленская Д. Б. Интеллектуальная активность как проблема творчества. Москва: Интелл, 2015. $274 \mathrm{c}$.

4. Виноградова Л. В. Развитие мышления учащихся при обучении математике. Петрозаводск : Карелия, 1989. 175 с.

5. Дружинин В. Н. Психология общих способностей : учебное пособие. 3-е издание. СанктПетербург : Питер, 2007. 368 c.

6. Истомина Н. Б. Активизация учащихся на уроках математики в начальных классах. Москва : Просвещение, 1985. 63 с.

7. Лернер И. Я. Развивающее обучение с дидактических позиций // Педагогика. 1996. № 2. С. 7-11.

8. Пономарев Я. А. Психология творчества и педагогика. Москва : Наука, 1976. С. 76-91.

\section{Соколова Л.А. \\ Развитие эмоционального интеллекта у подростков в условиях тематических смен: результаты эмпирического исследования}

ФГБОУ ВО «Костромской государственный университет» (Россия, Кострома)

doi: $10.18411 / l j-07-2021-154$

Аннотация

В статье рассматриваются особенности развития эмоционального интеллекта у подростков в условиях тематических смен. Проанализированы результаты эмпирического исследования развития эмоционального интеллекта у подростков.

Ключевые слова: подростковый возраст, эмоциональный интеллект, тематическая смена. 